\section{Commentary: Radical root resection for prosthetic valve endocarditis}

\author{
Clancy W. Mullan, MD, Arnar Geirsson, MD, and \\ Roland Assi, MD, MMS
}

Double-valve endocarditis involving the aortic and mitral valves represents one of the most formidable challenges in cardiac surgery, with outcomes limited to descriptions at the institutional level, notable for in-hospital mortality in the range of $9 \%$ to $32 \% .^{1}$ Data on double prosthetic valve endocarditis remain even more sparse, and virtually no information exists on root replacements with a Commando operation. In this edition of the Journal, Aphram and colleagues present their approach to radical resection and reconstruction of the aortic root, aortomitral continuity, and both valves in a challenging case of double prosthetic valve endocarditis. ${ }^{2}$

This degree of aggressive resection followed by equally extensive reconstruction is certainly appealing in its likelihood of source control during the operation; however, as a technical report, information on complications of this approach is needed for the community to gauge its effectiveness and safety. Extrapolating from some of the largest cohorts of aortic root replacement for endocarditis, prosthetic valve endocarditis, and Commando operations, one could anticipate an operative mortality of at least $10 \%$ to $15 \%$, pacemaker requirements of at least $15 \%$ to $20 \%$, and prolonged ventilation in a majority of patients. ${ }^{1,3,4}$ While potentially high reward, this surgical endeavor certainly is high risk, and patients and their families should be appropriately counseled.

The current American Association for Thoracic Surgery guidelines for the management of endocarditis include a class I recommendation for a multidisciplinary approach to

\footnotetext{
From the Division of Cardiac Surgery, Department of Surgery, Yale School of Medicine, New Haven, Conn.

Disclosures: The authors reported no conflicts of interest.

The Journal policy requires editors and reviewers to disclose conflicts of interest and to decline handling or reviewing manuscripts for which they may have a conflict of interest. The editors and reviewers of this article have no conflicts of interest.

Received for publication July 9, 2021; revisions received July 9, 2021; accepted for publication July 16, 2021; available ahead of print July 21, 2021.

Address for reprints: Roland Assi, MD, MMS, 330 Cedar St, Boardman 204, New Haven, CT 06519 (E-mail: roland.assi@yale.edu).

JTCVS Techniques 2021;9:28-9

2666-2507

Copyright (C) 2021 The Author(s). Published by Elsevier Inc. on behalf of The American Association for Thoracic Surgery. This is an open access article under the CC BY-NC-ND license (http://creativecommons.org/licenses/by-nc-nd/4.0/). https://doi.org/10.1016/j.xjtc.2021.07.012
}

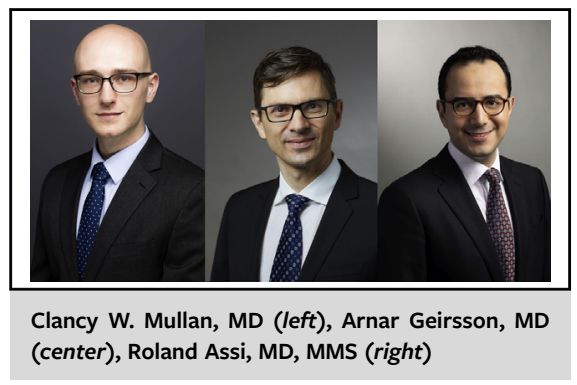

CENTRAL MESSAGE

Aphram and colleagues present an excellent how-to for their approach to aortic-mitral double prosthetic valve infective endocarditis with root and aortomitral continuity involvement.

endocarditis on top of a class I recommendation for cardiac surgical teams with "mastery of the necessary reconstructive procedures." As described, these multidisciplinary teams should include infectious disease, cardiology, and cardiac surgery with access to any medical or surgical subspecialty that could be required to provide complete care of the infected patient, including, for example, nephrology, neurology, vascular surgery, neurosurgery, and addiction medicine. Needless to say, one can expect these to be resource-intensive patients. As the authors dutifully highlight, their operation was performed at a center with decades of experience in managing these complex patients, consistent with the aforementioned guidelines.

In our experience, the pool of patients requiring redo aortic root operations after 1 or more previous valve operations is expanding. This is in part because of the ongoing opioid crisis in North America, as well as the aging population with degenerating bioprosthetic valves. We agree with the authors that a clean radical operation is necessary. However, even after the most radical operations, outcomes are hindered by the underlying cardiomyopathy, severe comorbidities such as renal and hepatic failure, and disease recurrence in the case of illicit drug use relapse.

Despite its name, "The Commando," being borrowed from otolaryngology, the title for this harrowing operation is apt when one considers its militaristic origin. The primary objective in the surgical management of this complex and morbid condition is to achieve source control, restore function, and get the patient through the hospitalization alive. Aphram and colleagues should be congratulated for their excellent depiction and masterful handling of an incredibly challenging problem. 


\section{References}

1. Navia JL, Elgharably H, Hakim AH, Witten JC, Haupt MJ, Germano E, et al. Long-term outcomes of surgery for invasive valvular endocarditis involving the aortomitral fibrosa. Ann Thorac Surg. 2019;108:1314-23.

2. Aphram G, Jahanyar J, de Kerchove L, El Khoury G. En-bloc aortic root resection and commando procedure for aortomitral bioprosthetic endocarditis. J Thorac Cardiovasc Surg Tech. 2021;9:25-7.

3. Sultan I, Bianco V, Kilic A, Chu D, Navid F, Gleason TG. Aortic root replacement with cryopreserved homograft for infective endocarditis in the modern North American opioid epidemic. J Thorac Cardiovasc Surg. 2019; 157:45-50.

4. Weber C, Petrov G, Luehr M, Aubin H, Tugtekin SM, Borger MA, et al. Surgical results for prosthetic versus native valve endocarditis: a multicenter analysis. $J$ Thorac Cardiovasc Surg. 2021;161:609-19.e10.

5. Pettersson GB, Coselli JS, Hussain ST, Griffin B, Blackstone EH, Gordon SM, et al. 2016 the American Association for Thoracic Surgery (AATS) consensus guidelines: surgical treatment of infective endocarditis: executive summary. $J$ Thorac Cardiovasc Surg. 2017;153:1241-58.e29. 